\title{
Análise das bases epistemológicas do campo teórico da política educacional*
}

\author{
Analysis of the epistemological foundations of the \\ theoretical field of education policy
}

\section{Análisis de las bases epistemológicas del campo teórico de la política educativa}

Elione Maria Nogueira Diógenes*

\begin{abstract}
Resumo: Este artigo desenvolve ponderações pertinentes às bases epistemológicas do campo teórico das políticas públicas de educação, situando e contextualizando, historicamente, seu desenvolvimento. $\mathrm{O}$ texto introduz uma reflexão sobre a influência dos paradigmas dominantes das ciências sociais que fundamentam os estudos nessa área e, também, reconstrói os itinerários históricos da temática a partir do comparecimento do Estado educador na formulação e na implementação das políticas públicas de educação no Brasil. O artigo aproxima-se de alguns estudos cujas correntes teóricometodológicas assumem o materialismo-histórico-dialético de investigação. A principal conclusão é a de que os paradigmas críticos dominam tais estudos. Além disso, as bases epistemológicas das políticas públicas de educação têm como argamassa hegemônica, do ponto de vista contemporâneo, o campo da Ciência Política.
\end{abstract}

Palavras-chave: Política Educacional. Estado. Bases Epistemológicas.

\begin{abstract}
This paper develops relevant considerations to the epistemological foundations of the theoretical field of public education policy, situating and contextualizing historically its development. This text introduces a reflection on the influence of the dominant paradigms of the social sciences that underlie studies in this area, and also reconstructs the historical itinerary of the theme from the attendance of the State educator in the formulation and implementation of public policies on education in Brazil. This paper approaches some studies whose theoretical and methodological frameworks assume the historical and dialectical materialism research. The main conclusion is that the critical paradigms dominate such studies. Moreover, the

\footnotetext{
* Texto escrito com base na pesquisa sobre a Reforma do Ensino Médio no Brasil, desenvolvida sob a orientação da Prof . Dra. Maria Ozanira da Silva e Silva, no curso de Doutorado em Políticas Públicas, do Programa de Pós-Graduação em Políticas Públicas (PPGPP) da Universidade Federal do Maranhão (UFMA). O estudo foi financiado pelo CNPq. Agradeço, ainda, a referida Professora pela presença inestimável em minha trajetória intelectual e profissional. A ela, devo, sobretudo, o compromisso ético com o ato de pesquisar, portanto, aqui expresso minha gratidão.

** Professora da Universidade Federal de Alagoas (UFAL). E-mail: <elionend@uol.com.br>
} 
epistemological foundations of public education policies have as hegemonic mortar, from the contemporary point of view, the field of Political Science.

Keywords: Education Policy. State. Epistemological Foundation.

Resumen: Este artículo desarrolla ponderaciones pertinentes a las bases epistemológicas del campo teórico de las políticas públicas de educación, situando y contextualizando, históricamente, su desarrollo. El texto introduce una reflexión sobre la influencia de los paradigmas dominantes de las ciencias sociales que fundamentan los estudios en esa área y, también, reconstruye los itinerarios históricos de la temática a partir de la asistencia del Estado educador en la formulación y en la implementación de las públicas de educación en Brasil. El artículo se encuentra próximo de algunos estudios cuyas corrientes teóricometodológicas asumen el materialismo-histórico-dialéctico de investigación. Además, las bases epistemológicas de las políticas públicas de la educación tienen como cimento hegemónico, desde el punto de vista contemporáneo, el campo de la ciencia política.

Palabras clave: Política educativa. Estado. Bases epistemológicas.

\section{Breves notas à guisa de introdução}

A epistéme relativa ao domínio das políticas públicas de educação tem forte influência das Ciências Sociais (particularmente da Sociologia), da Filosofia e da Ciência Política (dentre outras). Isso porque não há uma epistemologia exclusiva dessa temática. Como explicita Faria (2003), esse campo é permeado pela multidisciplinaridade. Em verdade, a expressão "políticas públicas" surge em contexto histórico e social, cujo papel do Estado, no que diz respeito à gestão da educação, consolida-se com o poder político da burguesia. Isso vale singularmente para o Brasil a partir da revolução burguesa de 1930 (FERNANDES, 1975). Nisso a política educacional tem um nexo orgânico com as relações envolvendo o Estado e a sociedade civil.

Para Silva (2001, p. 44), o tema "políticas públicas" consiste em um "[...] campo de estudo da pesquisa social em desenvolvimento". Isso se aplica, também, às políticas públicas de educação e ajuda a compreender que tal temática situa-se em uma linha de fronteira, portanto os pressupostos epistemológicos, filosóficos, políticos e sociais (que lhe dizem respeito) atravessam a análise dos paradigmas que estão na base das formas de organização social e políticas assumidas pela sociedade atual. Não há, pois, um "modelo" unívoco de pesquisa nesse campo. O sentido é o de que tem abrangência histórica articulada com a dinâmica das transformações sociais, econômicas, políticas e culturais de uma determinada sociedade, e com a sua capacidade de resolver ou não os problemas e os dilemas de sua época. 
A política educacional é parte das políticas públicas a partir da concepção de que: "Toda política pública é uma forma de regulação e intervenção na sociedade" (SILVA, 2001, p. 37). Höfling (2001, p. 31) completa tal assertiva ao colocar que as políticas públicas podem ser compreendidas como responsabilidade do Estado quanto à "[...] implementação e manutenção a partir de um processo de tomada de decisões que envolvem órgãos públicos e diferentes organismos e agentes da sociedade relacionados à política implementada". Igualmente Jobert e Muller (1987) compreendem as políticas públicas como o "Estado em ação", em processo de implantação de um projeto de governo hegemônico, por meio da criação, da formulação e da implantação de programas, de projetos e de ações voltadas a tais ou quais classes sociais.

Sob essa ótica, o Estado não se reduz à burocracia pública, em que os organismos estatais planejam e programam as políticas públicas, agindo como mero instrumento de planejamento e execução dessas políticas. Muito menos um ente supra classista como na visão weberiana, mas é percebido, na ótica marxiana de Poulantzas (2000, p. 130), como “[...] uma relação, mais exatamente como a condensação material de uma de relação de forças entre classes e frações de classe, tal como ele expressa de maneira sempre específica, no seio do Estado".

O entendimento dessa relação como "[...] síntese de muitas determinações, isto é, unidade do diverso" (MARX, 1982, p. 14) e do referencial teórico quanto à perspectiva de política educacional adotada ressalta três aspectos essenciais aqui considerados: 1) a origem e o desenvolvimento dos estudos sobre as políticas públicas de educação; 2) a discussão sobre as referências teóricas clássicas nas ciências sociais; e 3) as tendências metodológicas e tipos de pesquisas desse campo. Há de acrescentar-se um quarto aspecto não menos importante, a saber: a aplicabilidade de pesquisas no âmbito das políticas públicas de corte educacional, com foco em projetos de sociedade, no interior do sistema capitalista.

\section{Chave histórica das políticas públicas de educação}

O delineamento do percurso histórico das políticas públicas de educação torna mais fácil entender as principais concepções e metodologias, os tipos e os modelos clássicos destas sem esquecer a materialidade histórica desses aspectos nem tampouco a sua íntima articulação com os paradigmas teóricos hegemônicos na área da pesquisa social nesse ou naquele contexto histórico. Isso é importante para compreender-se porque, atualmente, a política educacional é destacada como "[...] políticas públicas de corte social [...]" (SILVA, 2001, p. 37). Nem sempre foi assim. As políticas públicas de educação abrangeram diferentes 
momentos históricos até a sua predominância a partir de meados dos anos 90 do século XX em diante.

Nagel (2003, p. 30), ao considerar o contexto histórico das políticas públicas de educação, reconhece que "[...] há uma diretividade educacional sistematizada e defendida na sociedade" Com isso, as políticas públicas de educação modificam-se no interior das relações estabelecidas entre o Estado capitalista e a sociedade civil e dependem do grau de intervenção desse Estado nas questões sociais a partir da formulação e da implementação das políticas e dos programas de caráter educacional como potencializadores ou não de melhorias na estrutura social. A principal reflexão de efeito, nesse caso, é a de que existem relações importantes a serem apreciadas quando se analisa essa ou aquela questão referente às políticas públicas de educação. Höfling (2001, p. 30) considera que uma dessas relações "[...] consideradas fundamentais é a que se estabelece entre Estado e políticas sociais, ou melhor, entre a concepção de Estado e a(s) política(s) que este implementa, em uma determinada sociedade, em determinado período histórico".

As relações entre Estado e políticas educacionais tomam esse ou aquele contorno nessa ou naquela determinação histórica. Do desenvolvimento inicial do capitalismo concorrencial ao capitalismo monopolista e imperialista, passando pela atual fase de reestruturação capitalista da produção, o Estado metamorfoseou-se e as políticas públicas de educação acompanharam essa dinâmica de transformação, com avanços ou recuos conforme a dinâmica impressa nesse ou naquele contexto histórico.

No Brasil, a origem das políticas públicas de educação registra-se nas décadas de 1930/1940 com a revolução burguesa e a ascensão da classe burguesa enquanto classe dirigente hegemônica (DRAIBE, 1989; MELO, 1999). Portanto, em outros momentos da sua História, a formulação de políticas públicas de educação nem sempre esteve articulada com a pesquisa científica sobre elas.

Podemos dizer que a pesquisa em educação começou a consolidar-se como um campo de estudo a partir da década de 40 do século XX, aproximadamente, com a criação do Instituto Nacional de Estudos e Pesquisas Educacionais - INEP - e suas regionais em diferentes lugares do País. (KRAWCZYK, 2011, p. 3).

Isso explica, em parte, a predominância de estudos técnicos levados a efeito principalmente pelo INEP, relegando, muitas vezes, pressupostos teóricometodológicos que levam em consideração o contexto mediato e imediato, mediado pelas relações de produção. Há no campo da pesquisa das políticas educacionais um forte recrudescimento nas duas últimas décadas do século XX e no início do XXI em diante que se deve à implantação "[...] de um vasto 
conjunto de programas de pós-graduação no País, no final da década de 1960, pelo qual se transferiu para as universidades o espaço de produção científica e de formação de quadros" (KRAWCZYK, 2011, p. 3).

A relação entre esse movimento e a "[...] grande transformação [...]" (POLANYI, 2000, p. 17) - iniciada ainda no século XIX e aguçada no contexto do pós-guerra -, que as sociedades de capitalismo avançado têm experienciado é latente, ainda que possa parecer tardio. As políticas públicas inscrevem-se no interior de um tipo especial de Estado: "São formas de interferência do Estado, visando à manutenção das relações sociais de determinada formação social" (HÖFLING, 2001, p. 30).

Bem contextualizadas as transformações sociais, é importante informar que quando existia a bipolaridade geopolítica, ou seja, de um lado o capitalismo norte-americano e de outro o socialismo real da ex-República Soviética, as políticas públicas de educação não ficaram imunes a essa dinâmica de política internacional. Passados mais de trinta anos, o socialismo do Leste Europeu ruiu frente à ofensiva capitalista dos EUA e o neoliberalismo tornou-se hegemônico (PETRAS, 1999; MORAES, 1996; ANDERSON, 1995). A situação social da classe trabalhadora, que não era confortável nas décadas do século XX anteriores as duas guerras mundiais, só tem se agravado desde então, quando o Estado de bem-estar social europeu foi perdendo paulatinamente terreno para o Estado neoliberal, que, ao redefinir as funções estatais, formula programas “ $[$...] direcionados aos mais pobres, tendo em vista a garantia de um mínimo de sobrevivência [...]" (SILVA, 2003, p. 239).

Nesse terreno contraditório, em que o papel do Estado passou por um reordenamento profundo, no sentido de "diminuir de tamanho" enquanto conditio sine qua non à liberdade extrema de funcionamento do mercado, implicando em uma separação institucional das funções exclusivas e não exclusivas do Estado, as políticas públicas educacionais ganharam uma centralidade como instrumento estratégico de desenvolvimento social, com características demarcadas no âmbito da administração e da gerência dos programas e dos projetos implantados pelo governo. As políticas públicas de educação no cenário atual é fruto das transformações nas relações entre o Estado e a sociedade civil, culminando com o reordenamento da administração pública, que, na implantação de seus programas e projetos, prioriza os resultados.

Minayo (1991), Castro (1989), Cohen e Franco (2004) acrescentam a essa abordagem o contínuo avanço tecnológico incorporado, pelos gestores públicos, das novas tecnologias de informação e de comunicação e, ainda, os avanços institucionais da restauração da ordem democrática. Tal análise é coerente, acrescendo que não existem separações entre uma e outra realidade, ambas são faces 
de uma mesma moeda e estão inseridas no contexto das respostas encontradas pela classe burguesa dirigente à crise do Estado capitalista do pós-1970, que, no entanto, só vai se expressar globalmente na década de 1990 em diante. Nesse Estado reconfigurado pelos ditames do capital:

O novo padrão de acumulação não gera mais uma expansão do mercado (de trabalho e de consumo) como nos "anos dourados do desenvolvimento keinesiano-fordista". O processo de globalização e de integração regional vem progressivamente delimitando o espaço e os temas da soberania nacional e reduzindo - embora não eliminando - o poder de intervenção dos cidadãos e atores coletivos em diversas decisões públicas nacionais. (ABREU, 1993, p. 8).

No interior das novas relações entre Estado e sociedade civil, as políticas educacionais passam a figurar como essenciais e constituem-se em um amplo campo de pesquisa multidisciplinar. O retorno do interesse no campo da pesquisa educacional dá-se, dessa vez, não somente nos países de capitalismo avançado, mas nos países periféricos ou em desenvolvimento, os quais são influenciados, de uma forma ou de outra, pelas políticas econômicas dimanadas dos países economicamente dominantes, mediatizadas pelas instituições multilaterais. "Existe, inegavelmente, uma estreita relação entre as instituições multilaterais e as políticas públicas nos países em desenvolvimento" (ALMEIDA, 2005, p. 184). Essa análise explica porque o avanço dos estudos sobre política educacional, produzidos no Brasil, é datado a partir das duas últimas décadas do século XX em diante. A compreensão da construção teórica quanto à pesquisa em políticas públicas educacionais é importante para este trabalho, pois a educação "[...] está intrinsecamente relacionada ao desenvolvimento do conhecimento humano" (BARREIRA, 2002, p. 17).

\section{Correntes teórico-metodológicas e modelos clássicos dominantes na área da política educacional}

Figueiredo e Figueiredo (1986, p. 16) argumentam que a pesquisa em políticas públicas utiliza “[...] métodos próprios da pesquisa social”, ou seja, é uma atividade de investigação "[...] marcada durante toda a sua realização pelo quadro teórico que o pesquisador adota, por sua visão do mundo e compromisso social assim como pelos limites do conhecimento, próprios de seu tempo" (MINAYO, 1991, p. 233). Partindo desse pressuposto e da assertiva de que a pesquisa em "[...] políticas e programas sociais é um campo de estudo da pesquisa social em desenvolvimento" (SILVA, 2001, p. 44), pode-se, sem receio, afirmar que esta se insere no movimento mais geral de desenvolvimento das abordagens teórico-metodológicas que orientaram e orientam as atividades de produção do conhecimento das ciências sociais, processo em permanente construção. 
Importa sublinhar que não há uma teoria e uma metodologia em separado para as pesquisas em políticas públicas de educação. Estas sofreram e sofrem as influências dos paradigmas teóricos dominantes no século XX, cuja gênese grava-se nos séculos anteriores, mais notadamente no século XIX. Os grandes paradigmas que influenciaram as pesquisas em ciências sociais podem ser agrupados da seguinte forma: positivismo, materialismo histórico dialético, sociologia compreensiva e sociologia reflexiva. Comte e Durkheim, Marx, Weber e Bourdieu deixaram um legado teórico incomensurável, categoricamente impossível de esgotar.

O campo das políticas públicas de educação "[...] cresceu na esteira do método científico [...]” (BARREIRA, 2002, p. 19). As concepções e os tipos ou modelos clássicos dominantes das pesquisas em políticas educacionais estão intrinsecamente relacionadas tanto às referências teóricas quanto às abordagens metodológicas que, por sinal, não estão dissociadas do contexto histórico-social predominante de sua época. A reflexão que se empreende é, então, basilar no entendimento desta abordagem, cuja concepção metodológica tem "[...] referência aberta ou implícita [...]” (IANNI, 1994, p. 149) em uma das “[...] teorias mobilizadas para a pesquisa [...]" (IANNI, 1994, p. 149), implicando em "[...] pressupostos, conceitos, posturas teóricas, sistematizações intelectuais, proposições políticas, enfim, concepções de mundo e sociedade diferentes" (HÖFLING, 2001, p. 32).

O debate sobre os paradigmas teóricos que nortearam e norteiam a produção científica no campo da pesquisa da política educacional não pode ser relegada a um segundo plano. Toda a produção seja de caráter técnico ou mesmo científico do século XX, de forma indubitável, traz a marca do pensamento dos clássicos do século XIX. Infelizmente, o escopo deste artigo não tem como propósito aprofundar o tema aqui, mas as reflexões feitas permitem compreender as influências de um ou de outro paradigma, e mais do que isso: permite assinalar a inscrição política dessa produção, uma vez que não há neutralidade e imparcialidade no trabalho do pesquisador. Entender as concepções teóricas que embasam as pesquisas em políticas públicas de educação é fundamental para também apreender as abordagens metodológicas, os modelos e as tipologias em que se classificam de forma a identificar melhor o seu papel, sem esquecer que é uma "[...] oportunidade de reflexão crítica da ação [...]" (BARREIRA; CARVALHO, 2001, p. 8).

De todo modo, as abordagens metodológicas das políticas públicas educacionais estão circunscritas em uma temporalidade histórica, em um campo de disputa teórica entre as concepções clássicas do pensamento científico, considerando que a produção científica é historicamente construída e se insere, por si própria, em uma determinada época histórica. Exemplo disso é a hegemonia da 
corrente positivista/funcionalista nesse campo. Desde o desenvolvimento inicial desse tipo de pesquisa nos EUA que o desenho metodológico das pesquisas em política educacional é fortemente marcado pelo interesse com a mensuração e a medição dos resultados. "Sem dúvida alguma as primeiras abordagens nesse campo foram fortemente influenciadas pelo pensamento positivista colocando demasiada ênfase na mensuração e exigindo rigor no isolamento de variáveis ou resultados imputáveis aos programas sociais.” (BARREIRA, 2002, p. 40).

Os primeiros estudos sobre políticas públicas foram marcados pelas abordagens "[...] comportamental e neutralista [...]" (FIGUEIREDO; FIGUEIREDO, 1986, p. 1). Consoante Guba e Lincoln (1988), a primeira geração de estudos nessa área nos EUA (1900-1930) preocupava-se em mensurar o desempenho dos alunos, no sentido de medir a sua produtividade. A segunda geração (1930-1950) trazia como interesse descrever se a política atingiu (ou não) seus resultados. Por sua vez, o objetivo da terceira geração (1950-1980) era mensurar, descrever os resultados da política; e, a quarta geração (a partir de 1980), apesar de revelar alguns avanços em direção à tendência de abordagem qualitativa, como sinaliza Denzin e Lincoln (2006), ainda permanece com o mesmo ideário, ou seja, pouco se mudou em termos de referencial metodológico.

Com tal escopo, privilegiava-se e privilegia-se a medição/mensuração dos objetivos elencados, de forma que se desconsideravam as variáveis contextuais em sua análise. Esse tipo de abordagem, até hoje predominante, "[...] ignora a política pública como uma intervenção na realidade, envolvendo os diferentes sujeitos e condicionada por interesses e expectativas" (GOMES, 2001, p. 19). Os estudos nos moldes positivistas têm "[...] sofrido fortes críticas: por sua perspectiva quantitativista; pelo seu caráter externo; pelas fragilidades metodológicas apresentadas [...]" (GOMES, 2001, p. 19).

Posta a questão, antecipa-se a discussão sobre a abordagem metodológica que comumente é associada ao positivismo. Nesse momento, a reflexão dirige-se à abordagem metodológica quantitativista ou abordagem quantitativa entendida como a preocupação com a descrição dos dados exteriores de uma dada realidade, buscando estabelecer nexos de causa-efeito para explicar essa ou aquela situação encontrada na pesquisa, com base em dados estatísticos descritivos.

Há, contudo, alguma relação entre a abordagem metodológica quantitativa e o paradigma positivista? Barreira (2002, p. 41) entende que a pesquisa embasada em métodos quantitativos está "[...] ancorada no paradigma positivista [...]". Silva (1998) também pensa assim, enfatizando que a “[...] posição epistemológica básica no positivismo clássico recusa a possibilidade de compreensão subjetiva dos fenômenos [...]" (SILVA, 1998, p. 3). O que se põe em questão aqui é a já tão criticada 'neutralidade científica', uma das premissas básicas do positivismo para 
as pesquisas, cuja abordagem "enclausura-se" em termos quantitativos. Apesar de não haver consenso no debate, o certo é que a abordagem quantitativa ressente-se de um excessivo domínio positivista em seus estudos ${ }^{1}$.

O positivismo e a abordagem quantitativa, na visão de Minayo e Sanches (1993), têm relação orgânica, pois a abordagem comtiana “[...] limita-se a observar os fenômenos e fixar as ligações de regularidade que possam existir entre eles, renunciando a descobrir causas e contentando-se em estabelecer as leis que os regem [...]" (MINAYO; SANCHES, 1993, p. 244). Com isso, há sim uma relação entre os postulados da abordagem quantitativa e do positivismo. $\mathrm{O}$ fato é que a primeira originou-se dos estudos de Comte e Durkheim. Ambos defendem que existe uma forma monolítica de se fazer ciências sociais: apreendendo o social por meio da observação dos dados, dos caracteres exteriores, "[...] objetivamente manifestos nos fatos [...]” (MINAYO; SANCHES, 1993, p. 243).

Mesmo com essas evidências teóricas entre positivismo e abordagem quantitativa, Gatti (2004) defende que colocar a abordagem quantitativa como eivada unicamente de positivismo é escamotear o debate, pois existem certos aspectos da realidade que para sua devida "[...] contextualização e compreensão necessitam ser qualificados através de dados quantitativos [...]” (GATTI, 2004, p. 13). Com isso: "Os métodos de análise de dados que se traduzem por números podem ser muito úteis na compreensão de diversos problemas" (GATTI, 2004, p. 13).

O que está em questão não é apenas a forma em que se dispõem os dados, mas o referencial teórico que fundamenta as pesquisas em políticas públicas de educação, pois é possível que o positivismo seja tão arraigado em posturas qualitativas quanto nas quantitativas. Por isso, atualmente, há uma tendência a se rever as posições no tocante não apenas à abordagem quantitativa ${ }^{2}$, mas à qualitativa igualmente, uma vez que novas e velhas questões apresentam-se no limiar do século XXI, em que não menos se fazem presentes intensos e acalorados debates, inclusive em torno dos mecanismos de construção e apreensão do conhecimento pela espécie humana.

Em oposição à abordagem quantitativa tem-se a qualitativa que são “[...] abordagens interativas que consideram no processo avaliativo, variáveis contextuais e processuais [...]" (SILVA, 2001, p. 46). Durante muitos anos a abordagem qualitativa permaneceu ofuscada diante da hegemonia quantitativa, no entanto:

\footnotetext{
${ }^{1}$ A abordagem quantitativa desde a sua origem está imersa no contexto da corrente positivista, daí ser identificada com tal paradigma, onde o enfoque prioritário é nos dados estatísticos e nos instrumentais técnicos e metodológicos.

${ }^{2} \mathrm{O}$ domínio teórico-metodológico da abordagem quantitativa ainda é muito forte no campo da pesquisa de políticas públicas no Brasil, entretanto, a partir da década de 1980, estudiosos (as) como Minayo e Sanches (1993), Deslandes (1997), Silva (2001), Gomes (2001), Barreira (2002) e Minayo (2006), dentre outros, têm destacado a importância da abordagem qualitativa.
} 
Há mais de três décadas, uma revolução metodológica silenciosa vem ocorrendo nas ciências sociais. Os limites disciplinares perderam sua nitidez. As ciências sociais e as humanidades passaram a aproximar-se cada vez mais, concentrando-se no mesmo foco de uma abordagem qualitativa, interpretativa para a pesquisa e a teoria. (DENZIN; LINCOLN, 2006, p. ix).

Silva (2001), Barreira (2002) e Minayo (2006) compartilham da visão de Denzin e Lincoln (2006) quando, em suas análises, enfatizam a fragilidade da abordagem metodológica quantitativista, que não consegue dar conta das variáveis contextuais de forma dialética. Deslandes (1997) acrescenta que, só no final dos anos 80, “[...] a supremacia dos dados quantitativos como suporte único para a pesquisa passou a ser revista [...]" (DESLANDES, 1997, p. 105). As críticas contundentes à ênfase dada meramente aos aspectos quantitativos na pesquisa de políticas públicas educativas fortalecem a abordagem qualitativa, quanto a: “(a) valores culturais e representações sobre sua história e tema específicos; (b) relações entre indivíduos, instituições e movimentos sociais; (c) processos históricos, sociais e de implementação de políticas públicas e sociais" (MINAYO, 2006, p. 23).

A abordagem qualitativa de perspectiva teórica crítica considera a pesquisa da política educacional como um processo que possui movimento, uma dinâmica própria, em que se analisa a ação de sujeitos sociais distintos na arena social de contradições, afirmando o seu caráter histórico e dinâmico, levando ao entendimento de que o real é instável, múltiplo, diferente e contraditório. Ou seja, está-se pisando no campo da dialética de investigação, pois, nessa teoria, os conceitos de contradição, de mudança e de superação desempenham papel crucial. O embasamento da análise é o movimento dos contrários, compreendendo que não se trata de uma "[...] oposição excludente entre o sim ou o não" (DESLANDES, 1997, p. 105), mas de uma totalidade concreta, isto é, unidade das contradições. A realidade é, pois, um devir, um vir-a-ser (LEFEBVRE, 1979).

Desse paradigma teórico retira-se a seguinte compreensão: somente com base na abrangência histórica em que se assenta a produção material da formação social e econômica de uma determinada sociedade é possível empreender uma pesquisa qualitativa na área das políticas públicas de educação, uma vez que esse tipo de abordagem metodológica é “[...] atividade situada [...]" (DENZIN; LINCOLN, 2006, p. 17), que contextualiza o "lugar" do pesquisador no mundo, pois:

Consiste em um conjunto de práticas materiais e interpretativas que dão visibilidade ao mundo. Essas práticas transformam o mundo em uma série de representações, incluindo as notas de campo, as entrevistas, as conversas, as fotografias, as gravações e os lembretes. Nesse nível, a pesquisa qualitativa envolve uma abordagem naturalista, interpretativa, para o mundo, o que 
significa que seus pesquisadores estudam as coisas em seus cenários naturais, tentando entender, ou interpretar, os fenômenos em termos dos significados que as pessoas a eles conferem. (DENZIN; LINCOLN, 2006, p. 17).

No entanto, o mesmo questionamento feito aos métodos de abordagem quantitativa tem se estendido aos de abordagem qualitativa, particularmente no âmbito das pesquisas de avaliação das políticas públicas. Não que se pretenda negar a sua validade, ao contrário: o que se põe como epicentro da discussão é se esta por si só consegue dar conta de todas as dimensões da realidade. Aqui se tem uma resposta negativa, até porque, lembrando Lênin, a realidade é mais rica do que qualquer teoria.

Ao refletir sobre isso, Minayo, Assis e Souza (2005) propõem a pesquisa por triangulação dos métodos quantitativos e qualitativos - é a abordagem quanti-quali que está cada vez mais sendo debatida na Academia e nas instituições que se dedicam à avaliação de políticas públicas. As autoras fazem um esforço bem sucedido de superação do que chama de "falsa" dicotomia entre abordagem metodológica quantitativa e qualitativa. No epicentro da discussão sobre a triangulação dos métodos, está posta a questão da multidisciplinaridade - tema caro aos pesquisadores na construção de uma práxis científica que supere a dicotomia entre sujeito e objeto da pesquisa, dando conta tanto das dimensões objetivas quanto das subjetivas.

Daí a proposta da triangulação de métodos, ou seja, a síntese entre abordagem quantitativa e qualitativa, gerando a abordagem quanti-quali. A idéia é simples: combinar métodos quantitativos com abordagem qualitativa, no sentido de permitir a análise das representações sociais e das diferentes posições dos grupos sociais que formam o universo da pesquisa. Minayo (2006), ao propor a triangulação, faz um movimento no sentido de retomar o debate acerca das diferenças entre as abordagens quantitativa e qualitativa, no sentido de forçar um diálogo entre ambas superando, como já ressaltado, a tão propalada dicotomia. Entretanto, a questão é bem mais complexa e está situada (a meu ver) em outro nível de discussão: trata-se não apenas de como se formula e se elabora o conhecimento, mas a serviço do que e de quem está o conhecimento. Pois bem, é a questão já não tão velha que não possa ser trazida à tona e que foi posta por Marx (1888) na tese onze do escrito dirigido a Feuerbach: "Os filósofos têm apenas interpretado o mundo de diferentes maneiras; a questão, porém, é transformá-lo" (MARX, 1986, p. 210).

A compreensão que alicerça tal entendimento é a de que o processo de conhecimento da realidade social é um organismo político que pode e deve orientar as classes sociais subordinadas à lógica do capital na luta pela transformação da sociedade. Para Marx, a legitimidade ou a prova de fogo da teoria está no campo 
da prática que deve validar ou não a pertinência da teoria na explicitação ou análise da realidade vivida. "A questão de saber se ao pensamento humano pertence à verdade objetiva não é uma questão da teoria, mas uma questão prática. É na práxis que o ser humano tem de comprovar a verdade, isto é, a realidade e o poder, o caráter terreno do seu pensamento." (MARX, 1986, p. 208).

Vistas por esse ângulo, as abordagens metodológicas qualitativas e quantitativas da pesquisa em políticas públicas educacionais ganham nova dimensão, que se presentifica na seguinte pergunta: qual a preocupação dos pesquisadores na área das políticas públicas em educação ao realizarem suas pesquisas? Se a resposta for marcada de alguma forma pela "[...] inquietação de tornar os conhecimentos produzidos mecanismos instrumentalizadores das lutas sociais" (SILVA, 2001, p. 126), então a referência teórica norteadora é dialética, nisso se traduzindo sua vocação crítica.

\section{Políticas públicas de educação: modelos clássicos dominantes}

Os modelos clássicos demonstram, com especial vigor, a tendência de tal ou qual abordagem teórico-metodológica no desenvolvimento das pesquisas sobre políticas educacionais. Apesar de fugir da intenção - discutir em profundidade os diferentes tipos de pesquisa em políticas públicas de educação -, não é possível desconsiderar quais os aspectos teóricos determinantes em tais estudos nem tampouco as estratégias metodológicas que vêm sendo utilizadas como base para orientar as análises.

Existe uma vasta produção científica em torno dessa questão, mas não há consenso analítico, pois os estudiosos, na maioria das vezes, partem de pontos de vista diferentes, o que de qualquer forma revela as diferentes concepções acerca da temática, bem como a disputa teórica em torno dela. Indicam-se alguns estudos instigantes que bem podem orientar os leitores que estejam dispostos a conhecer um pouco mais de tão interessante campo de estudos ${ }^{3}$ : Saviani (2006), Kuenzer (1985, 1997, 2007), Severino e Fazenda (2003), Cury (1984, 1985), Frigotto (2003), Nosella (2005), Azevedo e Aguiar (2001), Barretto (1983) e Krawczyk e Vieira (2008), dentre outros. Estes, de uma forma ou de outra, estão envolvidos não apenas em estudos teóricos de pesquisas, mas têm uma considerável produção empírica em torno da temática, abordando de modo inclusivo os modelos clássicos de pesquisa.

Diferentemente do que ocorria no início da pesquisa em política educacional, de caráter positivista, os estudiosos citados são de vertentes que assumem a teoria crítica dialética na abordagem de seus estudos. O que significa dizer que,

\footnotetext{
${ }^{3}$ Essas obras são de matriz teórica crítica-reflexiva e podem ser consideradas estudos clássicos nessa área.
} 
de uma maneira ou de outra, eles consideram a dinâmica dialética e histórica em seus estudos.

No contexto atual, a realidade não é muito diferente. Ao pesquisar 30 artigos nos periódicos da CAPES durante uma década (2001 a 2011), foi possível averiguar que a vertente analítica desses periódicos tem sido dominada pela linhagem crítica. Com a Era das reformas educacionais no Brasil, tal situação tem permanecido. Tome-se como exemplo os estudos que tratam da questão do Ensino Médio. Este tem sido foco desde 1996 de políticas educacionais, com o propósito de implantar a reforma Novo Ensino Médio: Educação agora é para a vida, compreendida no contexto mais amplo da reforma educacional da década de 1990, cujo marco legal é a Lei de Diretrizes e Bases da Educação Nacional n ${ }^{\circ}$ 9394/96.

Em linhas gerais, a reforma educacional de abrangência macro centrou-se em instaurar processos de descentralização e de democratização das escolas públicas de todo o país, nos quadros do reordenamento do Estado brasileiro (LEITÃO, 2005; JESUÍNO, 2005). Quanto à reforma do Ensino Médio, esta tem como núcleo as metamorfoses impetradas no mundo do trabalho, com as exigências impostas pelo novo mercado de trabalho em tempos de reestruturação produtiva do capital e de financeirização da economia. Consultando a Resolução n. 03/98, um dos principais documentos da reforma, constatou-se que a preocupação é com a organização pedagógica e curricular de cada unidade escolar, no sentido de que esta adeque seu currículo ao mundo do trabalho e "[...] tendo em vista vincular a educação com o mundo do trabalho e a prática social, consolidando a preparação para o exercício da cidadania e propiciando preparação básica para o trabalho" (BRASIL, 1998, p. 21).

Desde sua implantação, a reforma do Ensino Médio tem sido estudada pela academia e outras instituições com o intuito de se compreender suas especificidades e implicaçoes ${ }^{4}$. No entanto, para efeito do tema aqui abordado, interessa sobremaneira os estudos que se dedicaram a entender a reforma por meio de pesquisas científicas levadas a efeito em Programas de Pós-Graduação em Educação, como assinalado no início deste artigo, uma vez que o objetivo é identificar e analisar as concepções e modelos clássicos de pesquisa dominantes, conforme a literatura desenvolvida por esse campo do saber. Não se trata apenas de localizar tais estudos, mas de realizar um esforço extra, com fins de compreender os tipos de pesquisa vigentes e, mais do que isso, as referências teórico-metodológicas hegemônicas. Bem situadas essas pesquisas pode-se delimitar sua importância para uma maior compreensão.

\footnotetext{
${ }^{4}$ Ver os estudos de Machado (1998, 2002), Macedo e Lopes (2002), Barretto (2002) e Zibas (2001).
} 
Assim, foi feito um levantamento bibliográfico sobre o que se produziu acerca da temática da reforma do Ensino Médio na primeira década do século XXI, e foram selecionados os estudos referentes à pesquisa dessa política. A grande maioria dos estudos ${ }^{5}$ sobre a reforma em foco percebe-a de forma dialética. São excelentes estudos, sérios, clássicos, de análise crítica da política de extrema relevância para a compreensão das idiossincrasias que a permeiam. Entretanto, não trabalham com a categoria de "políticas públicas", utilizando o referencial paradigmático explicitado por Silva (2001), Barreira (2002) e Arretche (1999, 2001).

Arretche (1999) faz uma demarcação entre "[...] uma pesquisa de uma dada política [...]" e uma "[...] pesquisa política e análise de políticas públicas [...]" (ARRETCHE, 1999, p. 29). A primeira envolve essencialmente um julgamento, um juízo de valor, tratando de atribuir uma opinião valorativa. A segunda é necessariamente "[...] o exame da engenharia institucional e dos traços constitutivos dos programas [...]" (ARRETCHE, 1999, p. 30). Nisso, a autora vai ao encontro do pensamento de Figueiredo e Figueiredo quanto enfatizam que a pesquisa política da política é uma "[...] análise e elucidação do critério ou critérios que fundamentam determinada política: as razões que a tornam preferivel a qualquer outra" (FIGUEIREDO; FIGUEIREDO, 1986, p. 2). De outra forma, a terceira busca reconstruir as diversas características das políticas públicas, tentando apreendê-las "[...] em um todo coerente e compreensível [...]" (ARRETCHE, 1999, p. 30), no sentido de dar organicidade as razões de ser da política.

Tomando esse paradigma como norte para este trabalho, os estudos de Zibas (2005), Krawczyk (2003) e Martins (2000) foram relacionados como pesquisas sobre o Ensino Médio. Para efeitos dessa tarefa, destacou-se de cada autora um trabalho. A primeira estudiosa é pesquisadora da Fundação Carlos Chagas e desenvolve estudos no campo da pesquisa sobre o Ensino Médio há pelo menos uma década. Sua produção sobre esse tema é vasta, mas traz-se para análise o texto A reforma do ensino médio no Ceará e suas contradições, resultado parciais de duas pesquisas, como a autora mesma revela. A primeira teve como objetivo "[...] acompanhar a implantação da reforma do ensino médio em três estados" (ZIBAS, 2005, p. 1). A segunda buscou identificar como a escola apropriou-se dos conceitos de "protagonismo juvenil e protagonismo dos pais", dois eixos da reforma (ZIBAS, 2005, p. 1).

De Krawczyk (2003) tem-se o texto A escola média: um espaço sem consenso. A estudiosa, professora da Universidade Estadual de Campinas (UNICAMP), foi junto a Zibas (2001-2003) responsável pela pesquisa sobre o processo de implementação da reforma do Ensino Médio em três estados brasileiros. No referido

\footnotetext{
${ }^{5}$ A título de exemplo cita-se: Kuenzer (2000, 2002), Martins (2000), Lopes (2002a, 2002b).
} 
texto, propõe-se discutir o processo de implementação da reforma do Ensino Médio no Ceará. Krawczyk tem uma considerável produção não apenas na área do Ensino Médio, mas também sobre a reforma educacional da década de 1990 e acerca da relação da reforma educacional do referido período (em diante) com as políticas públicas do Estado brasileiro.

A terceira estudiosa, Martins (2000), é pesquisadora da Fundação Carlos Chagas e professora da Universidade Católica de Santos (UNISANTOS). Ela tem produção científica em torno da temática da reforma educacional no Brasil e do Ensino Médio. O texto que dela se traz para análise tem como título Diretrizes curriculares nacionais para o ensino médio: pesquisa de documento. O interesse da autora é realizar uma análise dos fundamentos da reforma do Ensino Médio, discutindo os elementos-chave propostos pelas Diretrizes Curriculares Nacionais elaboradas pelos técnicos do Ministério da Educação (MEC), nos idos de 1998, quando da implantação da reforma do Ensino Médio.

Os dois primeiros trabalhos, de Zibas (2005) e de Krawczyk (2003), são resultados da pesquisa do processo de implementação da reforma do Ensino Médio. Nesse sentido, são ambos os estudos de pesquisa focada na implementação, entendendo esse momento como crucial no ciclo das políticas públicas. Tal momento é a "[...] fase do processo das políticas públicas que sucede à formação" (SILVA, 2001, p. 39). Isso significa dizer que se materializa no momento de execução da política, em que são realizadas as principais estratégias e tomadas de decisões fundamentais que interferem na proposta original de formulação.

Arretche (2001) define a fase de implementação como um "campo de incertezas" porque é nesse momento que a ação dos implementadores, pessoas que vão executar o programa, toma relevância central. Na sua argumentação, a autora destaca dois aspectos fundamentais: de um lado, a realidade local onde a política será implementada, e, de outro, a cooperação ou não dos agentes que não participaram do primeiro momento, isto é, da formulação. No primeiro caso, é perfeitamente factível que a instância local "distorça" a proposta original, e, no segundo, os implementadores podem resistir a executar fielmente as propostas desenhadas na engenharia institucional do programa. De um lado ou de outro, a ação dos implementadores interfere e muito no desenvolvimento do programa, acarretando "[...] dificuldades da autoridade central para obter sucesso na implementação de seus programas" (ARRETCHE, 2001, p. 48). Isso porque "[...] a implementação é, de fato, uma cadeia de relações entre formuladores e implementadores situados em diferentes posições na máquina governamental" (ARRETCHE, 2001, p. 49).

Estudando respectivamente os trabalhos de Zibas (2005) e de Krawczyk (2003), não nos foi possível perceber se as autoras atentaram para essas questões 
tão importantes levantadas por Arretche (2003). Entretanto, ficou claro que as autoras procuraram fazer uma pesquisa de implementação do processo da reforma do Ensino Médio, apontando os pontos críticos. Zibas (2005, p. 1) especifica, no início do texto, sua preocupação em "[...] acompanhar, por dois anos, o desenvolvimento da reforma em oito escolas estaduais de Fortaleza". Quanto à Krawczyk (2003),

[...] o intuito é analisar os principais eixos das reformas estaduais e seus focos mais críticos, a partir do estudo de seus diferentes aspectos e das tensões geradas entre a intencionalidade das novas estratégias, a realidade que se quer transformar e o que foi efetivamente produzido como decorrência das medidas propostas. (KRAWCZYK, 2003, p. 1).

Tanto em uma como em outra, há uma ênfase explícita na fase de implementação da política (como já referido), observando a proposta original de formulação e o que foi, de fato, implementado. Quanto à concepção e ao perfil da pesquisa, averiguou-se que ambas as pesquisas assumiram uma abordagem qualitativa, utilizando procedimentos metodológicos por meio de observações, análise de documentos e entrevistas que "[...] focalizaram não só os sujeitos da comunidade escolar (alunos, pais, professores, gestores) como também técnicos da Secretaria da Educação e membros de Sindicato" (ZIBAS, 2005, p. 202).

O texto de Martins (2000) pode ser inserido no modelo clássico de pesquisa conhecido como "pesquisa política da política", em que "[...] pretende-se avaliar os pressupostos filosóficos e sociais das diretrizes e dos parâmetros curriculares nacionais para o ensino médio" (MARTINS, 2000, p. 69). Ora, a ideia é realizar uma pesquisa crítica, levando em consideração que toda política está inserida em um dado contexto histórico, econômico e social. A autora parte do pressuposto de que as políticas do Ensino Médio, no caso a sua formulação concretizada nas diretriz̧es, "[...] expressam uma determinada concepção de educação, de escola e de conhecimento que deve ser olhada criticamente" (MARTINS, 2000, p. 69).

Na pesquisa política da política, o que determina a abordagem é a análise própria da política a partir de seus fundamentos, observando o que está posto nos documentos oficiais de formulação quanto aos princípios, aos objetivos e às características metodológicas da política. A autora analisa, também, o contexto social e econômico, e o papel desempenhado pelos principais formuladores da política. Assim, a pesquisa política da política torna-se um instrumento importante para desvendar a relação estratégica entre a política do Ensino Médio e a nova ordem econômica mundial.

Ao analisar a política do Ensino Médio por meio da pesquisa das Diretrizes Curriculares Nacionais para o Ensino Médio, principal documento norteador 
da reforma, Martins (2000) faz um estudo de profundidade em que a abordagem metodológica é de caráter eminentemente qualitativo. Assim, a autora está preocupada com o fato de que "[...] todo texto - ou toda prática discursiva - é uma prática social que predomina em determinado período histórico. Interessa, portanto, compreender as relações que a engendram e não apenas o discurso em si” (MARTINS, 2000, p. 79).

O trabalho de Martins (2000) junto aos de Zibas (2005) e de Krawczyk (2003) são exemplos reveladores de pesquisas na área do Ensino Médio. Apesar da primeira autora não identificar o seu estudo como "pesquisa política da política", o exame minucioso não deixa dúvidas quanto a inseri-lo nessa perspectiva. Os outros dois primeiros trabalhos deixam claro a sua intenção: acompanhamento e pesquisa da reforma do Ensino Médio. Ambos são estudos interessantes a partir do ponto de vista da pesquisa qualitativa.

\section{Considerações finais}

As "políticas públicas" não se localizam em um vazio temporal e histórico. Antes se relacionam com as perspectivas no campo da ação do Estado e da Sociedade Civil, equivalendo a dizer que é política de intervenção formatada na arena social, em que divergem interesses e racionalidades. Entretanto, na correlação de forças entre as classes sociais, hegemonicamente, tem-se vencedor um determinado projeto de sociedade. É nesse contexto que precisam ser compreendidas as políticas públicas desde a criação da agenda, passando pela formulação até a execução, bem como as especificidades dos diferentes modelos clássicos de pesquisa.

As pesquisas em políticas educacionais, por sua vez, são um campo de estudo da pesquisa social em desenvolvimento, e, como tal, necessitam ser estudadas e previamente analisadas, pois não há uma padronização cem por cento correta quanto ao referencial teórico-metodológico na abordagem de estudos científicos. O que se tem são objetos de estudos que demandam diferenciadas abordagens conforme os objetivos a que o pesquisador se propõe. Nesse caso, nunca é demais lembrar que a realidade é síntese de múltiplas determinações e que as variações contextuais precisam ser levadas em conta nos estudos de caráter avaliativo para que se evite cair nas armadilhas da neutralidade positivista.

Sob esse prisma de análise, as pesquisas realizadas com foco na reforma do Ensino Médio foram estudadas. Constatou-se que os estudos nesse campo trabalham com referencial teórico crítico. Uma lacuna que se deseja registrar diz respeito aos estudos sobre a reforma do Ensino Médio na linha de pesquisa sobre a avaliação dos impactos das políticas públicas de educação no cenário da escola média. 


\section{Referências}

ABREU, H. A trajetória e o significado das políticas públicas: um desafio democrático. Proposta, Rio de Janeiro, n. 59, p. 5-20, dez. 1993.

ALMEIDA, W. A trajetória das instituições financeiras multilaterais e suas relações com as políticas públicas. Revista de Políticas Públicas, São Luís, v. 9, n. 1, p. 173-216, jan./jun. 2005.

ANDERSON, P. Balanço do Neoliberalismo. In: SADER, E.; GENTILI, P. (Orgs.). Pósneoliberalismo: as políticas e o Estado democrático. Rio de Janeiro: Paz e Terra, 1995. p. $9-23$.

ARRETCHE, M. T. da S. Tendências no estudo sobre avaliação. In: RICO, E. M. (Org.). Avaliação de políticas sociais: uma questão em debate. 2. ed. São Paulo: Cortez: Instituto de Estudos Especiais, 1999. p. 1-10.

ARRETCHE, M. T. da S. Uma contribuição para fazermos avaliação menos ingênua. In: BARREIRA, M. C. N.; CARVALHO, M. do C. B. de. Tendências e perspectivas na avaliação de políticas e programas sociais. São Paulo: IEE/PUC/SP, 2001. p. 1-12.

ARRETCHE, M. T. da S. Dossiê agenda de pesquisa em políticas públicas. Revista Brasileira de Ciências Sociais - RCBS, São Paulo, v. 18, n. 51, p. 7-9, fev. 2003. DOI: 10.1590/S010269092003000100001

AZEVEDO, J. M. L.; AGUIAR, M. A. S. Políticas de educação: concepções e programas. In: ANPAE. Políticas e gestão da educação (1991-1997). Brasília: MEC/Inep/Comped, 2001. p. 43-51. (Série Estado do Conhecimento, n. 5).

BARREIRA, M. C. R. N. Avaliação participativa de programas sociais. 2. ed. São Paulo: Veras/CPIHTS, 2002.

BARREIRA, M. C. R. N.; CARVALHO, M. do C. B. de. Tendências e perspectivas na avaliação de políticas e programas sociais. São Paulo: IEE/PUC/SP, 2001.

BARRETTO, E. S. S. As novas políticas do ensino médio no contexto da educação básica. In: ZIBAS, D. M. L.; AGUIAR, M. A. S.; BUENO, M. S. S. O Ensino médio e a reforma da educação básica. Brasília: Plano, 2002. p. 253-265.

BARRETTO, E. S. S. Utilização das estatísticas educacionais pelos pesquisadores em educação. Brasília: MEC/Inep, 1983.

BRASIL. Resolução n 3, de 26 de junho de 1998. Diário Oficial da União, Brasília, 5 ago. 1998. Seção I, p. 21.

CASTRO, M. H. G. de. Avaliação de políticas e programas sociais. Cadernos de Pesquisa, Campinas, n. 12, p. 1-5, 1989.

COHEN, E.; FRANCO, R. Avaliação de projetos sociais. 6. ed. Petrópolis: Vozes, 2004.

CURY, C. R. J. Ideologia e Educação Brasileira: católicos e liberais. 2. ed. São Paulo: Cortez; Autores associados, 1984. (Coleção educação contemporânea).

CURY, C. R. J. Educação e contradição: elementos metodológicos para uma teoria crítica do fenômeno educativo. São Paulo: Cortez; Autores Associados, 1985. 
DENZIN, N. K.; LINCOLN, Y. S. Introdução: A disciplina e a prática da pesquisa qualitativa. In: DENZIN, N. K.; LINCOLN, Y. S. e colaboradores. O Planejamento da Pesquisa Qualitativa: teorias e abordagens. Tradução de Sandra Regina Netz. 2. ed. São Paulo: Artmed, 2006. p. 15-41.

DESLANDES, S. F. Concepções em pesquisa social: articulações com o campo da avaliação em serviços de saúde. Cadernos de Saúde Pública, Rio de Janeiro, v. 13, n. 1, p. 103-108, 1997. DOI: 10.1590/S0102-311X1997000100020

DRAIBE, S. As políticas sociais brasileiras: diagnósticos e perspectivas. In: IPEA. Instituto de Planejamento Econômico e Social. Para a década de 1990: prioridades e perspectivas de políticas públicas. Brasília: IPEA/IPLAN, 1989. p. 1-66.

FARIA, C. A. P. de. Idéias, conhecimento e políticas públicas: um inventário sucinto das principais vertentes analíticas recentes. Revista Brasileira de Ciências Sociais, São Paulo, v. 18, n. 51, p. 21-29, 51, fev. 2003. DOI: 10.1590/S0102-69092003000100004

FERNANDES, F. A Revolução Burguesa no Brasil. Rio de Janeiro: Zahar, 1975.

FIGUEIREDO, A. M. C.; FIGUEIREDO, M. F. Avaliação política e avaliação de políticas: um quadro de referência teórica. São Paulo: IDESP, 1986.

FRIGOTTO, G. Educação e crise no capitalismo real. 5. ed. São Paulo: Cortez, 2003.

GATTI, B. A. Estudos quantitativos em educação. Educação e Pesquisa, São Paulo, v. 30, n. 1, p. 11-30, jan./abr. 2004. DOI: 10.1590/S1517-97022004000100002

GOMES, M. de F. C. M. Avaliação de Políticas Sociais e cidadania: pela ultrapassagem do modelo funcionalista clássico. In: SILVA, M. O. da S. (Org.). Avaliação de políticas e programas sociais: teoria e prática. São Paulo: Veras, 2001. p. 17-35.

GUBA, E. G.; LINCOLN, Y. S. Effective evaluation. Improving the usefulness of evaluation results responsive and naturalistic approaches. San Francisco: Jossey-Bass Publishers, 1988.

HÖFLING, E. de M. Estado e políticas (públicas) sociais. Cadernos CEDES, Campinas, v. 21, n. 55, p. 30-41, nov. 2001. DOI: 10.1590/S0101-32622001000300003

IANNI, O. Globalização: novo paradigma das ciências sociais. Revista de Estudos Avançados, São Paulo, v. 8, n. 21, p. 147-163, maio/ago. 1994. DOI: 10.1590/S010340141994000200009

JESUÍNO, M. L. A. Autonomia escolar: para onde vai? 2005. 181 f. Dissertação. (Mestrado em Avaliação de Políticas Públicas) - Universidade Federal do Ceará, Fortaleza, 2005.

JOBERT, B.; MULLER, P. L'État en action: politiques publiques et corporatismes. Paris: PUF, 1987.

KRAWCZYK, N. A escola média: um espaço sem consenso. Cadernos de Pesquisa, São Paulo, n. 120, p. 169-202, nov. 2003. DOI: 10.1590/S0100-15742003000300009

KRAWCZYK, N. Reflexão sobre alguns desafios do Ensino Médio no Brasil hoje. Cadernos de Pesquisa, v. 41, n. 144, p. 754-771, set./dez. 2011. DOI: 10.1590/S010015742011000300006

KRAWCZYK, N.; VIEIRA, V. L. A reforma educacional na América Latina. Uma perspectiva histórico-sociológica (Argentina, Brasil, Chile e México na década de 1990). São Paulo: Xamã, 2008. v. 1. 
KUENZER, A. Z. O Ensino Médio agora é para a vida: entre o pretendido, o dito e o feito. Educação \& Sociedade, Campinas, v. 21, n. 70, p. 15-39, abr. 2000. DOI: 10.1590/S010173302000000100003

KUENZER, A. Z. A escola desnuda: reflexões sobre a possibilidade de construir o Ensino Médio para os que vivem do trabalho. In: ZIBAS, D.; AGUIAR, M. A.; BUENO, M. S. S. O Ensino médio e a reforma da educação básica. Brasília: Plano, 2002. p. 229-330.

KUENZER, A. Z. Ensino médio e profissional: as políticas do Estado neoliberal. 4. ed. São Paulo: Cortez, 2007.

KUENZER, A. Z. O Ensino Médio no contexto das políticas públicas de educação no Brasil. Revista Brasileira de Educação, Rio de Janeiro, n. 4, p. 77-95, jan./abr. 1997.

KUENZER, A. Z. Pedagogia da fábrica. São Paulo: Cortez, 1985.

LEFEBVRE, H. Lógica formal. Lógica dialética. Rio de Janeiro: Civilização Brasileira, 1979. LEITÃO, E. M. D. O Plano de Desenvolvimento da Escola em foco: uma análise da educação no Ceará em tempos de ajustes neoliberais. 2005. 364 f. Dissertação. (Mestrado em Avaliação de Políticas Públicas) - Universidade Federal do Ceará, Fortaleza, 2005.

LOPES, A. C. Os Parâmetros curriculares nacionais para o ensino médio e a submissão ao mundo produtivo. Educação e Sociedade, Campinas, v. 23, n. 80, p. 389-403, set. 2002a. DOI: $10.1590 /$ S0101-73302002008000019

LOPES, A. C. Parâmetros curriculares para o ensino médio: quando a integração perde seu potencial crítico. In: LOPES, A. C.; MACEDO, E. Disciplinas e integração curricular: história e políticas. Rio de Janeiro: DP\&A, 2002b. p. 145-176.

MACEDO, E.; LOPES, A. C. A Estabilidade do currículo disciplinar: o caso das ciências. In: LOPES, A. C.; MACEDO, E. Disciplinas e integração curricular: história e políticas. Rio de Janeiro: DP\&A, 2002. p. 73-94.

MACHADO, L. R. de S. A institucionalização da lógica das competências no Brasil. ProPosições, Campinas, v. 13, n. 1 (37), p. 92-110, jan./abr. 2002.

MACHADO, L. R. de S. O Modelo de competências e a regulamentação da base curricular nacional e de organização do ensino médio. Trabalho e Educação, Belo Horizonte, n. 4, p. 79-95, ago./dez. 1998.

MARTINS, A. M. Diretrizes curriculares nacionais para o ensino médio: avaliação de documento. Cadernos de Pesquisa, São Paulo, n. 109, p. 67-87, mar. 2000. DOI: 10.1590/ S0100-15742000000100004

MARX, K. Para a crítica da economia política; salário, preço e lucro; o rendimento e suas fontes: a economia vulgar. Introdução de Jacob Gorender. Tradução de Edgar Malagodi et al. São Paulo: Abril Cultural, 1982.

MARX, K. Teses sobre Feuerbach. In: MARX, K.; ENGELS, F. Obras escolhidas. São Paulo: Alfa-ômega, 1986. p. 69-72.

MELO, M. A. As sete vidas da agenda pública brasileira. In: RICO, E. M. (Org.). Avaliação de políticas sociais: uma questão em debate. 2. ed. São Paulo: Cortez: Instituto de Estudos Especiais, 1999. p. 11-28. 
MINAYO, M. C. de S. Abordagem antropológica para avaliação de políticas sociais. Revista Saúde Pública, São Paulo, v. 25, n. 3, p. 233-238, jun. 1991. DOI: 10.1590/S003489101991000300012

MINAYO, M. C. de S. O desafio do conhecimento: pesquisa qualitativa em saúde. 9. ed. São Paulo: HUCITEC, 2006.

MINAYO, M. C. S.; ASSIS, S. G. de; SOUZA, E. R. de. (Orgs). Avaliação por triangulação de métodos: abordagem de programas sociais. Rio de Janeiro: Fiocruz, 2005.

MINAYO, M. C. S.; SANCHES, O. Quantitativo-qualitativo: oposição ou complementaridade? Cadernos de Saúde Pública, Rio de Janeiro, v. 9, n. 3, p. 239-262, jul./set. 1993. DOI: 10.1590/S0102-311X1993000300002

MORAES, A. C. de. O projeto neoliberal e o mito do Estado Mínimo. Lutas Sociais. São Paulo: PUC, 1996.

NAGEL, L. H. "O aqui e o agora”, sem “o ontem e o amanhã", nas políticas de educação. In: NOGUEIRA, F. M. G.; RIZZOTTO, M. L. F. (Orgs.). Estado e políticas sociais: Brasil Paraná. Cascavel: EDUNIOESTE, 2003. p. 29-40.

NOSELLA, P. A Educação e o mundo do trabalho: da sociedade industrial à sociedade pós-industrial. In: STEPHANOU, M.; BASTOS, M. H. C. (Orgs.). Coleção Histórias e Memórias da Educação no Brasil. São Paulo: Vozes, 2005. p. 243-256.

PETRAS, J. Neoliberalismo: América Latina, Estados Unidos e Europa. Blumenau: FURB, 1999.

POLANYI, K. A grande transformação: as origens da nossa época. 11. ed. Rio de Janeiro: Elsevier, 2000.

POULANTZAS, N. O Estado, o poder e o socialismo. Rio de Janeiro: Graal, 2000.

SAVIANI, D. A nova lei da educação (LDB): trajetória, limites e perspectivas. 10. ed. Campinas: Autores Associados, 2006.

SEVERINO, A. J.; FAZENDA, I. C. A. (Orgs.). Políticas educacionais: o ensino nacional em questão. Campinas. SP: Papirus, 2003.

SILVA, M. O. da S. e. Avaliação das políticas sociais: aspectos conceituais e metodológicos. In: SILVA, M. O. da S. e. (Org.). Avaliação de políticas e programas sociais: teoria e prática. São Paulo: Veras, 2001. p. 44-65.

SILVA, M. O. da S. e. A política pública de transferência de renda enquanto estratégia de enfrentamento à pobreza no Brasil. Repositório Institucional - Universidade Federal do Maranhão - UFMA, São Luís, v. 7, n. 2, p. 233-253, jul./dez. 2003.

SILVA, R. C. A falsa dicotomia qualitativo-quantitativo: paradigmas que informam nossas práticas de Pesquisas. In: ROMANELLI, G.; BIASOLI-ALVES, Z. M. M. Diálogos Metodológicos sobre Prática de Pesquisa. São Paulo: Legis-Summa, 1998. p. 26-38.

ZIBAS, D. A reforma do ensino médio no Ceará e suas contradições. Cadernos de Pesquisa, São Paulo, v. 35, n. 124, p. 201-226, jan./abr. 2005. DOI: 10.1590/S0100-15742005000100010

Recebido em 17/11/2014

Versão final recebida em 03/04/2014

Aceito em 10/04/2014 